\title{
A decade of growth: the 1999 membership report
}

$\mathrm{O}$ n July 1st, while most people in the National Capital Region celebrated Canada Day by waving the maple leaf and watching fireworks explode over Parliament Hill, the number crunchers at CAEP Central tabulated the vitality of the organization.

Membership in 1999 was 1248, an increase of 207 members $(19.9 \%)$ over 1998. This is the largest ever year-to-year increase and, since 1990, CAEP membership has nearly tripled (Fig. 1).

Active memberships grew by $32 \%$, reflecting an increased commitment to the organization. Active members now represent $65 \%$ of all CAEP members. Our link to the future - residents and students increased by $12.5 \%$ (Fig. 2).

Regionally, Ontario signed up 81 new members, the largest absolute increase and up 19\% over 1998. However, proportionally, membership grew 157\% in Newfoundland, doubled in the Territories and increased by $57 \%$ in Nova Scotia. Most other provinces had significant membership growth: Alberta and PEI with $25 \%$, Saskatchewan with 22\%, New Brunswick with $21 \%$, BC with $19 \%$ and Quebec with $13 \%$. Only Manitoba had a (slight) membership decline, at $7 \%$. The regional membership distribution is displayed graphically in Figure 3.

\section{Garth Dickinson, MD}

Associate Editor, CJEM

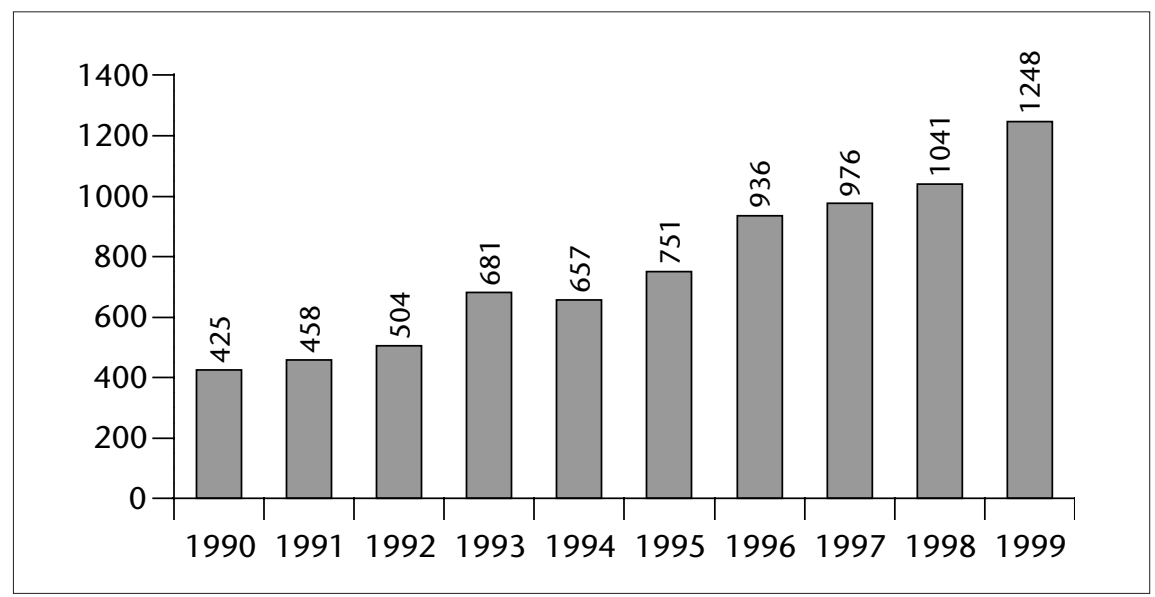

Fig.1. CAEP Membership 1990-1999

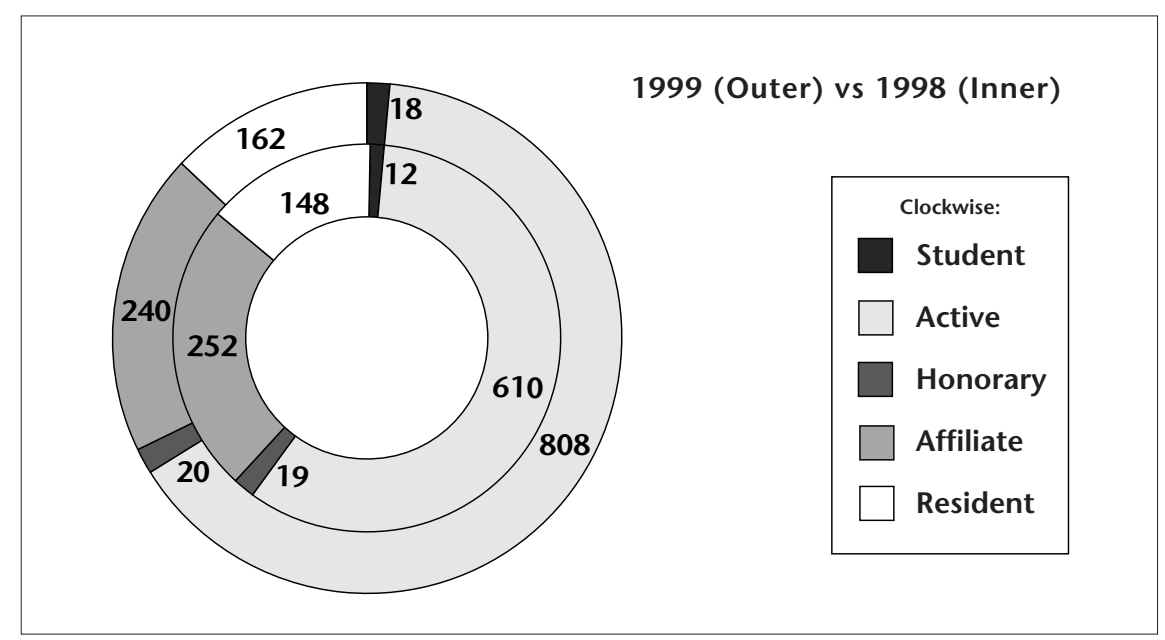

Fig. 2. Membership by Category

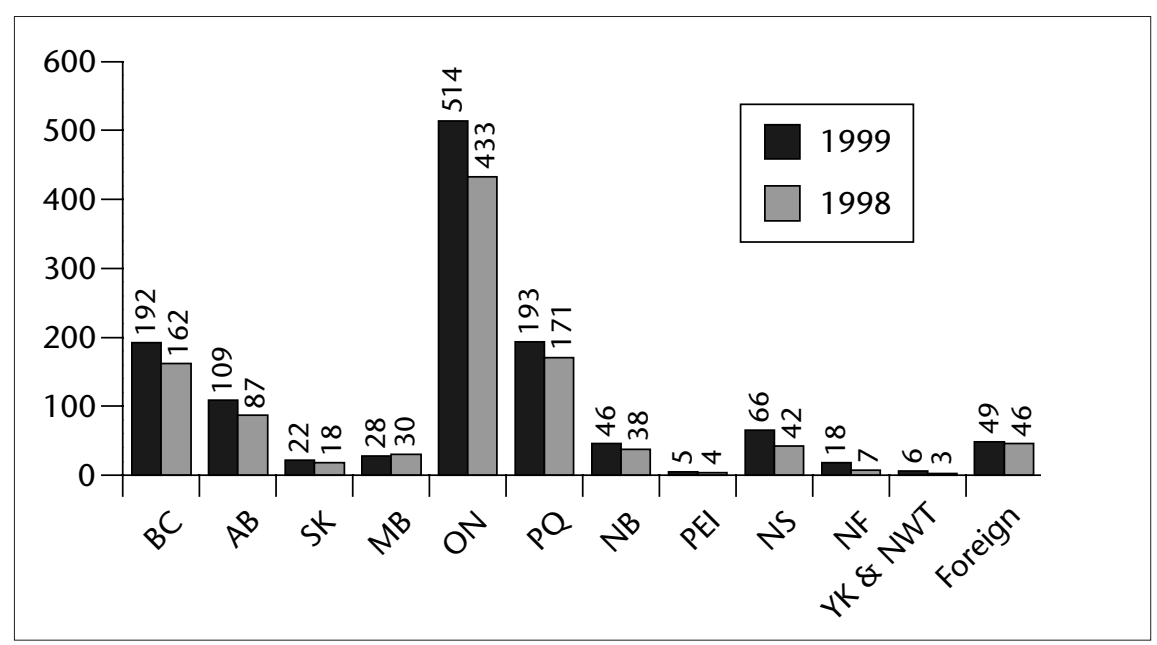

Fig. 3. Regional Distribution 